\title{
Crítica e invenção nas poéticas de João Cabral de Melo Neto e Manoel de Barros
}

\author{
Luiz Henrique Barbosa*
}

\begin{abstract}
RESUMO
Partindo da hipótese de que as poéticas de João Cabral de Melo Neto e Manoel de Barros são guiadas por um traço comum, o da convergência entre poesia e crítica, este estudo mostra as especificidades de cada poeta ao produzir poesia crítica e textos críticos sobre poesia. Chega-se à conclusão de que essa convergência tem por objetivo apresentar a matéria de poesia dos poetas: a eleição do elemento prosaico. É ressaltado que os dois poetas, ao elevarem ao estatuto de poesia elementos pouco nobres, ao fazerem da crítica a matéria fundamental de sua poesia, estariam renovando uma poesia que não se vale de tais elementos.

Palavras-chave: Crítica. Poesia. João Cabral de Melo Neto. Manoel de Barros.
\end{abstract}

Encontraremos em muitos poetas modernos a poesia convertida em metalinguagem, em espaço de reflexão crítica. Entretanto, muitos desses poetas não ficarão restritos ao trabalho com os poemas; vários deles irão produzir textos teóricos sobre o fazer literário. É importante ressaltar que essa confluência poesiacrítica se constituiu como uma via de mão dupla. Houve tanto uma aproximação da poesia em relação à crítica quanto desta em relação àquela. Expliquemos melhor. Do lado da poesia, encontraremos poetas que irão fazer do poema um espaço de discussão sobre o seu próprio fazer poético. Por meio dos poemas metalinguísticos, eles irão falar sobre o que desejam escrever, sobre a concepção poética que os guiam ou até mesmo sobre a dificuldade de se escrever. Ainda deste lado teremos os próprios poetas exercendo a atividade crítica fora do texto poético.

Por outro lado, encontraremos poetas que, além de uma produção poética, terão uma consistente produção crítica a respeito da literatura em geral, de seu próprio fazer poético, da pintura, da filosofia, da sociedade. Como exemplos poderíamos citar aqui Eliot, Valéry, Ezra Pound, Edgar Allan Poe, Mallarmé, Baudelaire, Octavio Paz e os brasileiros Augusto de Campos, Haroldo de Campos e João Cabral de Melo Neto. Em tais poetas, a atividade crítica que se deu fora 
do poema vai adotar a forma do ensaio. Este, entretanto, não será o único meio adotado pelos poetas para exercer sua atividade crítica. Segundo Maciel, "as cartas e os depoimentos (aqui podem ser incluídas as entrevistas) também foram e são exercitados como atividade crítica. Só que, à diferença dos outros textos, têm uma marca mais explicitamente subjetiva, sem contudo se furtarem à reflexão e ao rigor estético.” (MACIEL, 1994, p. 84)

Pensemos agora do lado da crítica. Encontraremos também uma confluência entre poesia e crítica entre aqueles que elegeram a crítica como sua principal atividade. Como observou Perrone-Moisés, percebemos um texto crítico tradicional como um discurso que desenvolve reflexões a respeito de uma questão precisa, "a obra crítica tradicional é uma dissertatio". (PERRONE-MOISÉS, 2005, p.87). E quais seriam os objetivos de uma dissertação crítica? Auxiliar os leitores em seu processo de compreensão de um objeto. Para ter sucesso em tal tarefa, elegem-se como objetivos principais a comparação, a classificação, a avaliação. Outra característica fundamental em tais textos se refere ao uso da linguagem adotada. Exige-se que o texto dissertativo adote uma linguagem científica, precisa, clara, sem as ambiguidades percebidas, por exemplo, no texto poético. Entretanto, encontraremos do lado dessa crítica-dissertatio uma crítica-escritura ${ }^{1}$, uma crítica criativa, uma crítica que irá incorporar em seu corpo características do texto científico e do texto poético. Tentaremos mostrar aqui como se dá o encontro crítica e poesia nas poéticas de João Cabral de Melo Neto e Manoel de Barros.

Para verificar a presença do elemento crítico na poesia de cada um, apresentaremos alguns poemas críticos e metalinguísticos e, para verificar a presença do poético nos textos críticos, debruçaremos-nos sobre os ensaios críticos de Cabral e as entrevistas por escrito de Barros publicadas na coletânea

\section{Gramática expositiva do chão.}

Iniciemos com João Cabral de Melo Neto. Podemos afirmar que a aproximação do poeta com a crítica já não é nenhuma novidade para o seu leitor. O próprio poeta já confirmou em uma série de entrevistas esse encontro, como podemos ver nessa seguinte passagem:

"Muito pouca gente notou isso, mas a minha poesia é sempre crítica. Esse negócio que se chama metapoesia, poesia sobre poesia, é uma preocupação de crítico. Escrevi uma quantidade enorme de poemas sobre autores, sobre escritores, sobre pintores. (MELO NETO apud ATHAYDE, 1998, p.25)

$1 \mathrm{O}$ termo escritura foi criado por Roland Barthes e a aparece pela primeira vez em sua obra $\mathbf{O}$ grau zero da escritura, publicada em 1953. 
A partir dessa declaração do poeta, poderíamos, em um primeiro momento, afirmar que a crítica estaria inserida em sua obra sob duas configurações: uma interna e outra externa. Expliquemos melhor. Encontraremos na obra de Cabral poemas autorreflexivos, que se voltarão para o próprio poeta em seu trabalho de criação. Este é o caso do poema "O funcionário", publicado no livro O engenheiro:

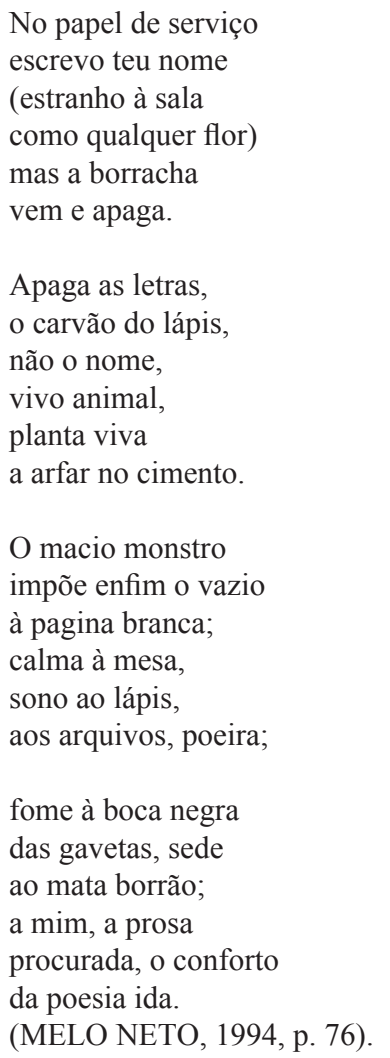

A respeito desse poema, podemos dizer primeiramente que ele irá dessacralizar o ato da criação poética. O poeta não é visto como um ser superior, que está acima da grande média dos mortais e que habita um lugar privilegiado. Tais elementos poderiam ser usados como explicação para o fato de o poema não poder ser produzido por qualquer um. O poema irá afastar-se dessa visão idealizada ao apresentar o poeta como um simples funcionário, que, em uma sala de seu local de trabalho, toma junto a si uma folha de papel em branco e tenta construir o seu texto. A visão do poema como um produto da inspiração, como produto de um 
sopro divino que iluminará o poeta será descartada. Em tal concepção poética, o poeta é menos um produtor do que um receptáculo daquilo que foge ao seu controle racional. Ao contrário disso, ele nos mostra que na criação poética a máquina racional do poeta é colocada em ação. E mais ainda: mostra-nos que esse ato da criação não é algo simples, de fácil conquista pelo poeta.

O tema do poema cujo processo de construção é discutido pelo poeta é a flor. Sabemos que a flor é uma metáfora tradicionalmente utilizada para se referir à palavra poética. Podemos pensar então que o poeta está abordando aqui as dificuldades do ato de escrever proporcionadas principalmente pelo seu grande nível de exigência. O poeta ficará em desvantagem na luta entre o branco imposto pela folha de papel vazia e a negra marca do carvão sulcada pelo lápis. A vida de cada nova palavra escrita será colocada a termo pela ação da borracha. O poeta irá se deparar então com a impossibilidade - mesmo que seja momentânea - do escrever e um ambiente de inatividade será então instaurado em contraposição aos objetos que estão envolvidos no ato de criação. Não haverá nenhuma movimentação na mesa, o lápis pegará no sono, os arquivos - possível fonte de criação - ficarão empoeirados, as gavetas ficarão famintas por não serem alimentadas pela produção do poeta e os mata-borrões que entram em ação na fase final da produção - quando o carvão do lápis é substituído pela tinta da caneta morrerão de sede. É interessante observar que, mesmo estando diante de uma certa infertilidade criativa, o poeta não assume uma postura pessimista. A ação imposta pelo seu próprio ato - o de apagar o que escreveu - impediu de fazer um poema sobre a flor, mas não uma "prosa" que discuta a dificuldade de escrever.

Como em vários poemas metalinguísticos, o poema em questão irá também colocar a nu o processo de ficcionalidade da literatura. Sabemos que há textos que escondem ou não se preocupam em explicitar o caráter representativo da literatura. No caso do poema acima, o poeta deixa claro que a poesia é representação de uma realidade exterior a ele. $\mathrm{O}$ que o poeta apaga é o signo, a palavra flor e não a "planta viva a arfar no cimento".

A dessacralização voltará a ser abordada em outro poema metalinguístico, “Antiode”, incluída no livro Psicologia da composição. Desta vez o poeta irá dessacralizar não mais o ato de criação poética, mas a própria poesia. Logo no início do poema já temos uma ideia de que o poeta irá criticar um tipo de poesia que se caracteriza por um certo requinte, por um conteúdo elevado. A ode é um texto poético tradicional que apresenta um caráter confessional. Ao abordar temas clássicos como o amor ou os prazeres, será inevitável o envolvimento emocional do poeta. O prefixo de negação anti presente no título nos permite pensar que 
estaremos diante de um texto que se coloca em oposição ao lirismo das odes. Isso é reforçado com a frase, colocada entre parênteses, que vem logo abaixo do título: "contra a poesia dita profunda". O poema, que é dividido em cinco seções, classificadas de A a E, constituir-se-á a partir da associação entre poesia, flor e fezes. A flor simbolizaria toda uma poesia de temas profundos - no poema em questão, as odes - enquanto fezes simbolizaria uma poesia que se afastaria da padronização das odes, uma poesia que, apesar de ser constituída de dejetos, de coisas rejeitadas pelo seu caráter de impureza, serão valorizadas pelo seu caráter inovador. ${ }^{2} \mathrm{Na}$ primeira seção, o poeta nos apresentará as duas visões de poesia, mas fará a opção pela de conteúdo elevado:

Poesia te escrevia:
flor! conhecendo
que és fezes. Fezes
como qualquer,
(...)
Delicado, evitava
o estrume do poema,
seu caule, seu ovário,
suas intestinações.
(MELO NETO, 1994, p. 98).

Valendo-se da metáfora da flor, o poeta, neste momento, associará a poesia apenas ao elemento visivelmente belo. É por isso que alguns elementos que não compõem a estrutura central da flor - suas pétalas, seu miolo - são rejeitados, apesar de a falta deles implicarem a não existência da flor. Sabemos que tanto o caule de uma flor - que se liga à terra, ao estrume - quanto seus elementos internos, abrigados pelo ovário, são fundamentais para a existência da mesma. No entanto, para o poeta, tais elementos são "impossíveis de poema", pelo menos de um poema que valoriza "as puras transparentes florações".

Vimos também que um outro lado dessa aproximação entre crítica e poesia é uma produção em prosa de poetas que, apesar de produzirem um texto informativo, tendo como base o princípio da dissertatio, irão incorporar a este texto elementos poéticos. Isso terá como consequência a existência de um texto híbrido, no qual estariam presentes a objetividade da dissertação e a criatividade do texto poético. No caso de João Cabral, não encontraremos a produção deste texto híbrido.

2 Segundo Peixoto, o teor de "Antiode" deslocar-se-á entre a crítica e o elogio. Ou seja, será criticada a poesia repetitiva, de caráter "idealizante" , representada aqui pela ode, e será elogiada a poesia criativa, que se afasta de um padrão já estabelecido. (Cf. PEIXOTO, 1983). 
Seus textos em prosa irão seguir os princípios básicos da dissertação: clareza, informação, objetividade. É o que ocorre no texto "Poesia e Composição". Nele Cabral mostrará que o processo de composição literária oscilará entre dois pontos: a inspiração e o trabalho de arte. Para o poeta, os autores guiados pela inspiração entenderão o poema como uma tradução da experiência vivida. O poema será algo recebido, guiado, muitas vezes, pela improvisação e não por um trabalho de construção do poeta. Nesse tipo de concepção poética, "é raro o poema sobre tal ou qual objeto. Quando esse poema ocorre, apenas comunica, do objeto, a visão subjetiva que o poeta se formou dele". (MELO NETO, 1994, p. 731). Ainda segundo Cabral, o poeta apresentará sempre uma postura passiva diante do poema, será sempre aquele que espera o poema.

Do lado dos poetas que adotam o trabalho de arte, haverá uma rejeição ao inefável, ao irracional, ao lirismo, a qualquer passividade. Essa concepção poética dará espaço ao poema objetivo, "ao poema no qual não entra para nada o espetáculo de seu autor e, ao mesmo tempo, pode fornecer do homem que escreve uma imagem perfeitamente digna de ser que dirige sua obra e é senhor de seus gestos". (MELO NETO, 1994, p. 733).

Passemos agora a examinar o encontro entre poesia e crítica na obra de Manoel de Barros. Também Barros terá grande parte de sua obra composta de poemas metalinguísticos que irão nos esclarecer sobre o seu processo de composição literária. Tomemos o poema "A borra", incluído em Ensaios Fotográficos:

Prefiro as palavras obscuras que moram os fundos de uma cozinha - tipo borra, latas, cisco Do que as palavras que moram nos sodalícios tipo excelência, conspícuo, majestade.

Também os meus alter-egos são todos borra, ciscos, pobres-diabos

Que poderiam morar nos fundos de uma cozinha

- tipo Bola Sete, Mário Pega Sapo, Maria Pelego

Preto etc.

Todos bêbedos ou bocós.

$\mathrm{E}$ todos condizentes com andrajos.

Um dia alguém me sugeriu que adotasse um alter-ego respeitável - tipo um príncipe, um almirante, um senador.

Eu perguntei:

Mas quem ficará com os meus abismos se os pobres-diabos não ficarem?

(BARROS, 2000, p. 61).

Embora Barros aponte em muitos de seus poemas a predileção pelo baixo, por 
aquilo que a sociedade pisa e rejeita ${ }^{3}$, esses elementos nunca figuram sozinhos no poema. Em seus textos haverá quase sempre uma opção pelo antitético. No caso do poema acima, apesar da opção de uma poesia que valoriza elementos pouco nobres como borra, latas, ciscos e pessoas que se encontram à margem da sociedade, um outro tipo de poesia, contrastante com essa será apresentada, aquela que usa palavras requintadas, que apresenta um corpus a ser utilizado pelos seus seguidores.

Sei que fazer o inconexo aclara as loucuras.

Sou formado em desenconcontros.

A sensatez me absurda.

Os delírios verbais me terapeutam.

Posso dar alegria ao esgoto (palavra aceita tudo).

(E sei de Baudelaire que passou muitos meses tenso porque não encontrava um título para os seus poemas.

Um título que harmonizasse os seus conflitos. Até que apareceu Flores do mal. A beleza e a dor. Essa antítese o acalmou.)

As antíteses congraçam. (BARROS, 1997, p. 49).

Além do gosto pelas antíteses, podemos afirmar que Barros irá admirar em Baudelaire o seu gesto de levar para a poesia o lixo, os párias, os seres desprezados pela sociedade. Sobre Baudelaire, Ivan Junqueira nos afirmará: “Contrariamente ao que sustentam Gautier e Banville, Baudelaire jamais cogitou de que poesia pudesse bastar-se a si mesma e, em lugar de uma estética do Belo, caberia atribuirlhe a criação de uma estética do Feio, que lhe embasa essa moderníssima liberdade de dizer tudo em poesia". (JUNQUEIRA apud BAUDELAIRE, 1995, p.81) É pelo princípio da liberdade que podemos explicar a existência também em Barros de poemas com temas tão diversos, de poemas que vão da sagração do lixo à referência de um autor ou de um pintor, como o que vem a seguir.
Miró
Para atingir sua expressão Fontana
Miró precisava de esquecer os traços e as doutrinas que aprendera nos livros.
Desejava atingir a pureza de não saber mais nada.
Fazia um ritual para atingir essa pureza: ia ao fundo do quintal à busca de uma árvore.

3 Castelo Branco mostrar-nos-á esta predileção do poeta pelo insignificante, pelo escatológico: “É nesse território úmido dos brejos e lodaçais que vamos encontrar a poesia de Manoel de Barros" (CASTELO BRANCO, 1995, p. 122) 
E ali, ao pé da árvore, enterrava de vez tudo aquilo que havia aprendido nos livros.

Depois depositava sobre o enterro uma nobre mijada florestal.

Sobre o enterro nasciam borboletas, restos de insetos, cascas de cigarra etc.

A partir dos restos Miró iniciava a sua engenharia de cores.

Muitas vezes chegava a iluminuras a partir de um dejeto de mosca deixado na tela.

Sua expressão Fontana se inicia naquela mancha escura.

O escuro o iluminava.

(BARROS, 2000, p. 29)

Debrucemos-nos agora especificamente sobre os textos críticos de Barros para verificarmos se existe neles a confluência do gênero poético e dissertativo. Como já ressaltamos anteriormente, Barros não possui uma produção ensaística sistematizada como a de Cabral e é por isso que nos deteremos sobre as entrevistas por escrito que ele concedeu a diversos periódicos do país. Sabemos que muitas de suas entrevistas que explicam seu processo de criação artística são guiadas pelo princípio da dissertatio. Ou seja, o poeta, ao falar de sua poesia, irá adotar o discurso científico, referencial, não se deixando "contaminar" pela linguagem criativa da poesia produzida por ele. No entanto, essa prática não será a única adotada por ele. Ao ser questionado sobre como é o seu processo de criação, ele responderá:

Como quem lava roupa no tanque dando porrada nas palavras. A escuma que restou no ralo vai ser boa para o começo. Depois é ir imitando os camaleões sendo pedra sendo lata sendo lesma. As palavras de nascer adubam-se de nós. Então no meio da coisa pode saltar uma clave ou um rato. Daí a gente tem que trabalhar. O horizonte fica longe que nem se vê. Um horizonte pardo como os curdos. Também faz parte desse processo desarrumar a cartilha. Seduz-me reaprender a errar a língua. Eis um ledo obcídio meu. (BARROS, 1990, p. 314)

No texto acima, as metáforas poéticas e o neologismo - presente na expressão "obcídio" - irão conviver com a referencialidade do texto dissertativo. Para dizer que é preciso retirar das palavras os sentidos já padronizados devido a seu uso regular na prática poética, o poeta empregará a imagem de uma lavadeira que bate a roupa no tanque para retirar da mesma a água que ela abriga. Para dizer que o poeta Barros elege como matéria de sua poesia elementos como latas e lemas, ele 
se vale da analogia do camaleão que se cola a esses objetos a ponto de se confundir com eles. Podemos afirmar que, nesse momento, Barros exerce a prática do textoescritura. O poeta se apropria das imagens poéticas, das analogias para produzir um conhecimento, para refletir e deixar claro para o leitor as técnicas utilizadas no seu processo de criação poética.

Ao discutirmos a aproximação entre poesia e crítica na poesia de Cabral e Barros, pudemos perceber várias semelhanças entre os poetas. Em Cabral percebemos o gesto de dessacralizar a poesia ao refletir sobre o seu processo de construção, mostrando inclusive as dificuldades encontradas pelo poeta ao produzi-la. Ainda nesse sentido - o da dessacralização - pode ser entendido o gesto do poeta de falar sobre tudo.

Em Barros, o mesmo processo de colocar a nu os modos de composição do poema é apresentado. Quanto à matéria eleita como conteúdo de poesia, pudemos verificar que em Barros parece haver uma maior intensidade na apresentação do elemento prosaico. Embora encontremos também em Cabral a tentativa de elevar a escória, os rejeitos ao estatuto de poesia, isso se dá em com maior frequência em Barros.

É importante ressaltar ainda o interesse de ambos os poetas pela desautomatização da poesia, pela produção de uma poesia que se renova a cada momento. É nesse sentido que podemos entender os caminhos trilhados pelos poetas. Ao elevarem ao estatuto de poesia elementos pouco nobres, ao fazerem da crítica a matéria fundamental de sua poesia, eles estariam renovando uma poesia que não se vale de tais elementos.

\begin{abstract}
Based on the hypothesis that the poetics of João Cabral de Melo Neto and Manoel de Barros are guided by a common theme, the convergence between poetry and criticism, this study shows the specificities of each poet in producing critical poetry and critical writing about poetry. The conclusion is that this convergence aims to present the substance of the poetry of both poets: the election of the prosaic element. It is emphasized that the two poets, raising little noble elements to the status of poetry, when making the critique the central matter of their poetry, were renewing a poetry that does not apply to such elements.
\end{abstract}

Keywords: Crític. Poetry. João Cabral de Melo Neto. Manoel de Barros. 
Referências

ATHAYDE, Félix de. Ideias fixas de João Cabral de Melo Neto. Rio de Janeiro: Nova Fronteira/ Mogi das Cruzes (SP): Universidade de Mogi das Cruzes, 1998. BARROS, Manoel de. Gramática expositiva do chão (poesia quase toda). Rio de Janeiro: Civilização Brasileira, 1993.

BARROS, Manoel de. Livro sobre nada. Rio de Janeiro: Record, 1997.

BARROS, Manoel de. Ensaios fotográficos. Rio de Janeiro: Record, 2000.

BAUDELAIRE, Charles. Poesia e prosa. Rio de Janeiro: Nova Aguilar, 1995.

CASTELLO BRANCO, Lúcia. Palavra em estado de larva. In: CASTELLO BRANCO, Lúcia; BRANDÃO, Ruth Silviano. Literaterras: as bordas do corpo literário. São Paulo: Annablume, 1995.

MACIEL, Maria Esther. Poéticas da lucidez: notas sobre os poetas-críticos da modernidade. Revista de estudos de literatura. Belo Horizonte: Faculdade de Letras da UFMG, v.2, p.75-96, out. 1994.

MELO NETO, João Cabral de. Obra completa. Rio de Janeiro: Nova Aguilar, 1994.

PERRONE-MOISÉS, Leyla. Texto, crítica, escritura. São Paulo: Martins Fontes, 2005. 